\title{
Experimental mouse model of optic neuritis with inflammatory demyelination produced by passive transfer of neuromyelitis optica-immunoglobulin $\mathrm{G}$
}

\author{
Nithi Asavapanumas ${ }^{1}$, Julien Ratelade ${ }^{1}$, Marios C Papadopoulos², Jeffrey L Bennett ${ }^{3}$, Marc H Levin ${ }^{4}$
} and Alan S Verkman ${ }^{1 *}$

\begin{abstract}
Background: Although optic neuritis $(\mathrm{ON})$ is a defining feature of neuromyelitis optica (NMO), appropriate animal models of NMO ON are lacking. Most NMO patients are seropositive for immunoglobulin G autoantibodies (NMO-lgG) against the astrocyte water channel aquaporin-4 (AQP4).

Methods: Several approaches were tested to develop a robust, passive-transfer mouse model of NMO ON, including NMO-IgG and complement delivery by: (i) retrobulbar infusion; (ii) intravitreal injection; (iii) a single intracranial injection near the optic chiasm; and (iv) 3-days continuous intracranial infusion near the optic chiasm.

Results: Little ON or retinal pathology was seen using approaches (i) to (iii). Using approach (iv), however, optic nerves showed characteristic NMO pathology, with loss of AQP4 and glial fibrillary acidic protein immunoreactivity, granulocyte and macrophage infiltration, deposition of activated complement, demyelination and axonal injury. Even more extensive pathology was created in mice lacking complement inhibitor protein CD59, or using a genetically modified NMO-IgG with enhanced complement effector function, including significant loss of retinal ganglion cells. In control studies, optic nerve pathology was absent in treated AQP4-deficient mice, or in wild-type mice receiving control (non-NMO) lgG and complement.

Conclusion: Passive transfer of NMO-lgG and complement by continuous infusion near the optic chiasm in mice is sufficient to produce ON with characteristic NMO pathology. The mouse model of NMO ON should be useful in further studies of NMO pathogenesis mechanisms and therapeutics.
\end{abstract}

Keywords: NMO, Neuroinflammation, Mouse models, Aquaporin, Astrocyte

\section{Background}

Neuromyelitis optica (NMO) is an autoimmune inflammatory disease of the central nervous system that causes demyelinating lesions in optic nerve and spinal cord, leading to loss of visual and motor function [1-3]. A specific feature of $\mathrm{NMO}$ is the presence of serum immunoglobulin $\mathrm{G}$ (IgG) autoantibodies (NMO-IgG) against astrocyte water channel aquaporin-4 (AQP4) [4,5]. NMO pathogenesis is thought to involve NMO-IgG binding to AQP4 on astrocytes, which causes complement- and cell-mediated astrocyte cytotoxicity, inflammation, and blood-brain barrier

\footnotetext{
* Correspondence: Alan.Verkman@ucsf.edu

'Department of Medicine and Physiology, University of California, 1246

Health Sciences East Tower, San Francisco, CA 94143-0521, USA

Full list of author information is available at the end of the article
}

(BBB) disruption, with secondary oligodendrocyte and neuron damage [6-8]. Current therapies of NMO include general immunosuppression, B-cell depletion and plasma exchange $[9,10]$.

Although optic neuritis $(\mathrm{ON})$ with permanent loss of vision is a major clinical feature of NMO [11-13], adequate models of $\mathrm{NMO} \mathrm{ON}$ are lacking. The particular sensitivity of the optic nerve in NMO suggests the need to study disease mechanisms and treatment responses in optic nerve-specific NMO models. Disease-relevant animal models of NMO are important for investigating pathogenesis mechanisms, such as the role of inflammatory effector cells [14-16] and for testing of potential therapeutics such as antibodies targeting AQP4 [17] or complement $[18,19]$. The original models of NMO involved 
administration of NMO-IgG to rats with pre-existing neuroinflammation produced by experimental autoimmune encephalomyelitis, in which immunization with a myelin oligopeptide produces an anti-myelin $\mathrm{T}$-cell response [20-22]. Subsequently, a passive-transfer mouse model of $\mathrm{NMO}$ involving intracranial injection of NMO-IgG and human complement recapitulated key pathological findings in NMO, including loss of AQP4 and glial fibrillary acidic protein (GFAP) immunoreactivity, granulocyte and macrophage infiltration, vasculocentric deposition of activated complement, and demyelination [23]. However, due in part to the limited diffusion of AQP4-IgG and complement from the injection site, pathology in this model was confined to a small region around the injection site, sparing the optic nerves.

The purpose of this study was to establish an animal model of NMO ON involving passive transfer of NMOIgG with targeted delivery to the optic nerves. Mice were chosen for these studies because of the availability of relevant knockout strains (AQP4 and CD59). After testing various approaches we established the conditions in which delivery of NMO-IgG to optic nerves produced $\mathrm{ON}$ with characteristic NMO pathology.

\section{Methods}

Mice

In vivo studies were performed on 8- to 10-week-old, weight-matched $\mathrm{AQP} 4^{+/+}$and $\mathrm{AQP} 4^{-/-}$mice in $\mathrm{CD} 1$ genetic background, which were generated as described previously [24]. Some experiments were done on $\mathrm{CD} 59^{+/+}$and $\mathrm{CD}_{59^{-/-}}$mice on a C57bl/6 background (provided by Dr Xuebin Qin, Harvard University, USA). Littermates were used as wild-type controls for the AQP4 and CD59 knockout mice. Mice were maintained in air-filtered cages and fed normal mouse chow in the University of California, San Francisco (UCSF) Animal Care facility. All procedures were approved by the UCSF Committee on Animal Research.

\section{Neuromyelitis optica (anti-aquaporin-4) antibodies}

Recombinant monoclonal NMO antibody rAb-53 (referred to as NMO-IgG) was generated from a clonally expanded plasma blast population from cerebrospinal fluid of an NMO patient, as described and characterized previously $[22,25]$. Purified rAb-53 was used for studies here because of its high affinity for AQP4, and to eliminate the potential variability introduced by using NMO patient serum, which is polyclonal and may contain other antibodies or soluble factors that influence NMO pathogenesis. A NMO 'superantibody' with enhanced complementdependent cytotoxicity (referred as $\mathrm{NMO}-\mathrm{IgG}^{\mathrm{CDC}+}$ ) was generated as described previously [26] by introducing mutations (G236A/S267E/H268F/S324T/I332E) in the Fc portion of rAb-53 [27].

\section{Neuromyelitis optica immunoglobulin G antibody delivery to anterior optic nerve and retina}

Adult mice were anesthetized with intraperitoneal tribromoethanol (avertin, 250 to $500 \mathrm{mg} / \mathrm{kg}$ ). Lateral canthotomy was done under a dissecting microscope. Ocular muscles were retracted and anterior optic nerve was exposed to infuse locally $1 \mu \mathrm{g}$ NMO-IgG and $0.5 \mu \mathrm{L}$ human complement (Complement Technology, Tyler, TX, USA) in a total volume of $1.5 \mu \mathrm{L}$. For intravitreal injection, a 32gauge needle attached to a $10-\mu \mathrm{L}$ gas-tight Hamilton syringe was passed through the sclera, next to the limbus, into the vitreous cavity. NMO-IgG ( 1 or $3 \mu \mathrm{g})$ and $0.5 \mu \mathrm{L}$ human complement in a total volume of $2 \mu \mathrm{L}$ was injected $(0.5 \mu \mathrm{L}$ per minute) above the optic nerve head.

\section{Neuromyelitis optica immunoglobulin G antibody delivery to posterior optic nerve}

Adult mice were anesthetized and mounted on a stereotaxic frame. A midline scalp incision was made and a burr hole of diameter $1 \mathrm{~mm}$ was drilled in the skull 1-mm right and $1-\mathrm{mm}$ anterior to bregma. For single administration of NMO-IgG, a 30-gauge needle attached to a 50- $\mu \mathrm{L}$ gastight syringe was inserted through the brain $(6 \mathrm{~mm}$ below the dura down to base of the skull) near the optic chiasm to deliver $5 \mu \mathrm{g}$ NMO-IgG and $5 \mu \mathrm{L}$ human complement in a total volume of $10 \mu \mathrm{l}$. For continuous administration of NMO-IgG, an osmotic minipump (Alzet 1003D, Cupertino, Ca, USA) delivered $3.3 \mu \mathrm{g}$ NMO-IgG and $16.7 \mu \mathrm{L}$ human complement per day for 3 days.

\section{Immunofluorescence}

Optic nerves were post-fixed for 2 hours in $4 \%$ paraformaldehyde. Ten micrometer-thick frozen sections were immunostained at room temperature for 1 hour with antibodies against AQP4 (1:200, Santa Cruz Biotechnology, Santa Cruz, CA, USA), GFAP (1:100, Millipore, Temecula, CA, USA), myelin basic protein (MBP; 1:200, Santa Cruz Biotechnology), ionized calcium-binding adaptor molecule-1 (Iba1; 1:1,000; Wako, Richmond, VA, USA), albumin (1:200, Santa Cruz Biotechnology), C5b-9 (1:100, Santa Cruz Biotechnology), neutrophil (Ly-6G, 1:100, Santa Cruz Biotechnology), eosinophil (siglec-F, 1:50, BD Biosciences, Oxford, UK), macrophage (F4/80, 1:100, Santa Cruz Biotechnology) or CD45 (1:10, BD Biosciences) followed by the appropriate fluorescent secondary antibody (1:200, Invitrogen, Grand Island, NY, USA). Immunofluorescence was examined with a Leica (Wetzlar, Germany) DM 4000 B microscope or Nikon (Melville, NY, USA) laser-scanning confocal microscope. Areas were defined by hand and quantified using ImageJ software (National Institutes of Health). 


\section{Retinal ganglion cell labeling}

Retinal ganglion cells (RGCs) were labeled as described previously [28-30]. Briefly, mice were injected with $1 \mu \mathrm{L}$ neurotracer dye FluoroGold (4\% solution in saline; Fluorochrome, Denver, CO, USA) in the superior colliculus (from the bregma, anterior-posterior, $-3 \mathrm{~mm}$; medial-lateral, $+0.5 \mathrm{~mm} ; 2 \mathrm{~mm}$ below the dura) 7 days before NMO-IgG and human complement delivery to posterior optic nerve. Retinas were flattened 14 days after the FluoroGold injection and whole-mounts were fixed in $4 \%$ paraformaldehyde. RGCs were counted manually under a fluorescence microscope with a $40 \times$ objective. A total of 16 to 20 images per retina were used for cell counting. As a positive control for RGC loss, optic nerve crush injury was produced by 30 -second compression of the optic nerve $2 \mathrm{~mm}$ posterior to the globe insertion using cross-action forceps. The optic nerve was accessed by lateral canthotomy and dissection beneath the lateral rectus. RGCs were quantified 7 days after crush.

\section{Statistical analysis}

Values are presented as mean \pm SEM. Comparisons between two groups were performed using the unpaired Student's $t$-test. $P<0.05$ was considered statistically significant.

\section{Results}

Passive transfer of neuromyelitis optica immunoglobulin $\mathrm{G}$ antibody and complement via retrobulbar infusion, intravitreal injection or single perichiasmal injection does not produce optic neuritis

Motivated by the success in creating NMO pathology in mouse brain by passive transfer of NMO-IgG and human complement by intracerebral injection [23], several approaches were tried to create $\mathrm{ON}$ or retinal cytotoxicity in mice. We first delivered NMO-IgG and complement to the anterior optic nerve by injection approximately $2 \mathrm{~mm}$ lateral to the anterior optic nerve following its exposure by lateral canthotomy. Figure 1A shows strong AQP4 expression in the anterior optic nerve, but only extradural deposition of NMO-IgG in surrounding skeletal muscle and soft tissue, as revealed using a fluorescently labeled anti-human secondary antibody (NMO-IgG is a human antibody). Attempts to increase contact time by using viscous gel vehicles were also unsuccessful in allowing access of NMO-IgG to optic nerve tissue, probably because of its dural ensheathment anterior to the optic canal.

We next tested intravitreal injection of NMO-IgG and complement to evaluate the potential for direct retinal injury, as AQP4 is strongly expressed on retinal Müller cells [31], and NMO-associated retinal abnormalities have been described [32-34]. As shown in Figure 1B,
NMO-IgG binding to the AQP4-expressing retinal Müller cells was detected with a secondary anti-human antibody. No binding of a control (non-NMO) IgG was seen. However no pathology was observed in the retina as judged by preserved AQP4 immunofluorescence (Müller cell marker), absence of CD45-positive inflammatory cells, and deposition of activated complement (C9neo immunostaining) (not shown). Also, NMO-IgG staining was absent in the optic nerve. We speculate that the absence of retinal pathology may be due to limited access of intravitreally injected complement proteins beyond the inner blood-retina barrier to Müller cells and/or their inactivation by soluble inhibitors of complement in vitreous fluid or retinal tissue.

Reasoning that the posterior optic nerve and optic chiasm lack the dura that encases the anterior optic nerve, we tested the delivery of NMO-IgG and complement by a single injection near the optic chiasm by an intracranial route, using stereotaxic methodology and a headbobbing sign to indicate needle contact with the cranial floor underlying the optic chiasm/posterior nerves (see Methods). The accuracy of needle placement was confirmed in preliminary studies in which dye-containing gels were injected and the optic nerves visualized following craniectomy. Figure 1C shows staining of the optic nerve periphery with NMO-IgG, with no staining by a control (non-NMO) IgG. While brain parenchyma near the optic nerve showed marked NMO pathology, little or no optic nerve pathology was seen, as evidenced by preservation of AQP4, GFAP and MBP (myelin) immunofluorescence, and absence of CD45-positive infiltrating leukocytes (not shown).

\section{Continuous perichiasmal infusion of neuromyelitis optica immunoglobulin $\mathrm{G}$ antibody and complement produces neuromyelitis optica optic neuritis}

We speculated that the absence of NMO pathology following a single perichiasmal injection of NMO-IgG and complement may be related to minimal contact time of the injected macromolecules with the optic nerve, as their diffusion in brain extracellular space is likely much faster than along the parallel white matter tracts of the optic nerve $[35,36]$. In order to promote sustained optic nerve exposure, NMO-IgG and complement were delivered continuously over 3 days using an implanted minipump with needle tip placement near the optic chiasm. Figure 2A shows Evan's blue dye distribution following 3-days mini-pump infusion, which includes areas of posterior prechiasmal optic nerves, optic chiasm, optic tract and surrounding brain parenchyma. Figure $2 \mathrm{~B}$ shows NMO-IgG binding to AQP4 in the brain parenchyma surrounding the needle tract. Figure $2 \mathrm{C}$,D shows substantial NMO-IgG deposition in optic nerves, with focal loss of AQP4 immunoreactivity, cell infiltration, and 


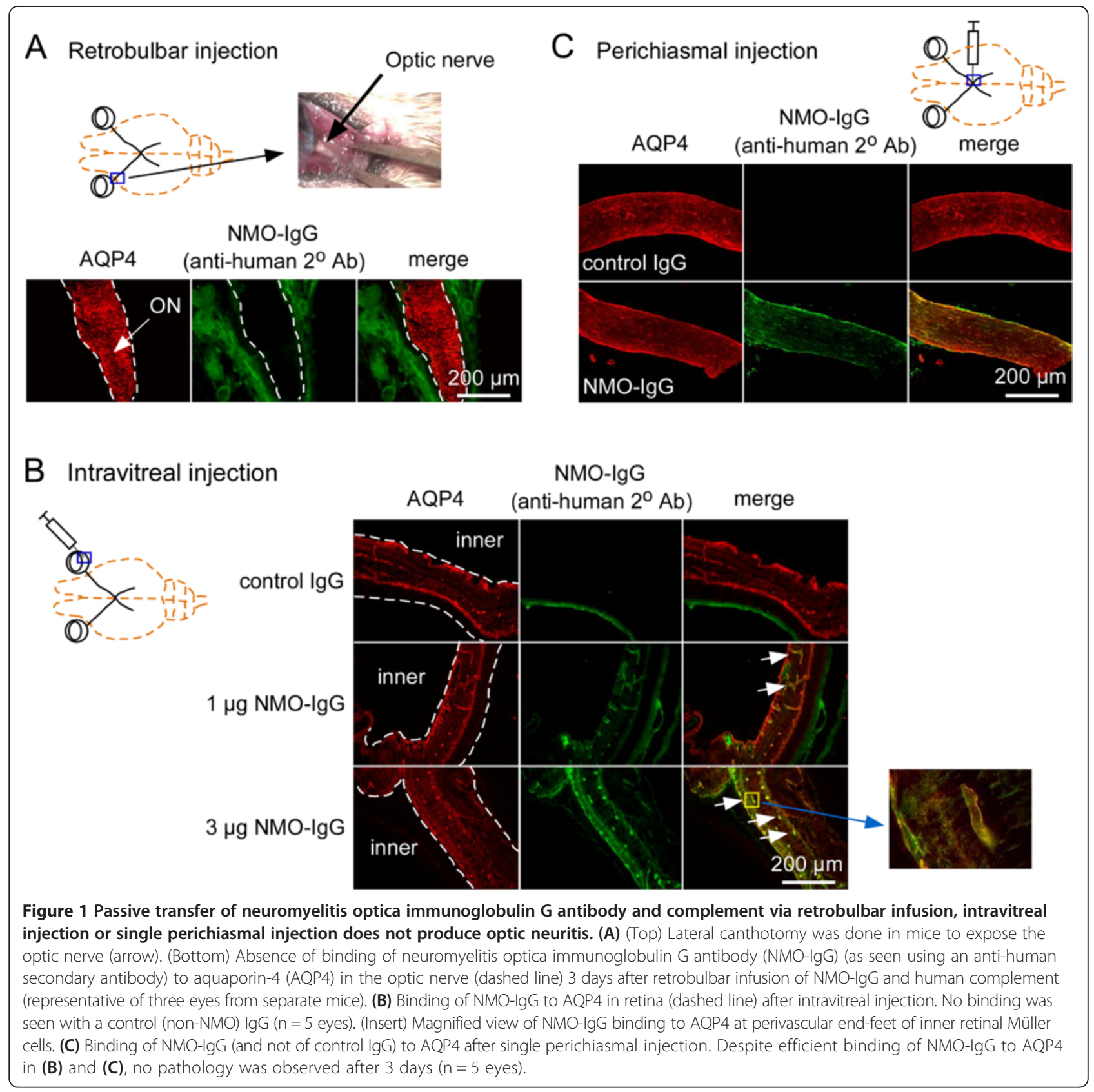

deposition of activated complement, indicating access of NMO-IgG and complement to the optic nerve, with development of NMO-like pathology. No lesions were seen following infusion of a control IgG and human complement.

Optic nerves were analyzed in 12 mice receiving a 3-day infusion of NMO-IgG and complement and 10 mice receiving the same quantity of control (nonNMO) IgG and complement. Eight out of 12 mice receiving NMO-IgG and complement showed characteristic NMO pathology in the optic nerve, with focal reductions in AQP4, GFAP, MBP and neurofilament immunofluorescence (Figure 3A). The precise site of the pathology was variable, likely reflecting slight variation in the location of the needle tip. None of the 10 mice receiving control IgG and complement developed pathology, nor did any of five mice receiving NMO-IgG alone (not shown), or of five AQP4 knockout mice receiving NMO-IgG and complement (Figure 3A). Development of optic nerve pathology therefore requires NMO-IgG and complement, as well as AQP4 expression.

Based on the central role of complement in NMO pathogenesis, we reasoned that increased complement activity would result in more profound optic nerve 


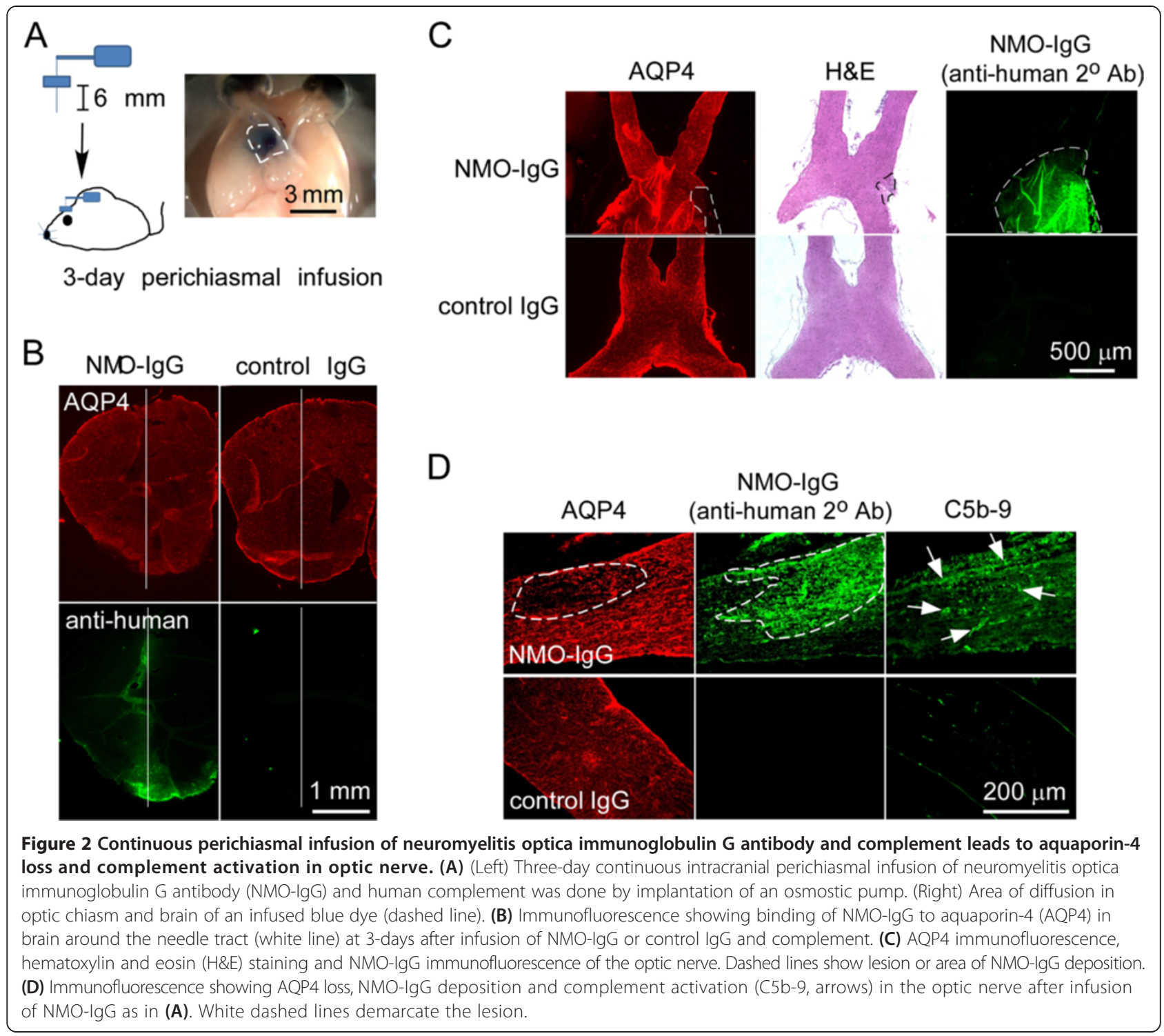

pathology. Two approaches were tested: (a) passive transfer of a mutated recombinant NMO-IgG (NMO-IgG ${ }^{\mathrm{CDC}+}$ ) having $~ 10$-fold increased complement effector function [26]; and (b) infusion in mice lacking CD59, the major membrane-associated complement inhibitor protein on mouse astrocytes [37,38]. Robust and more widespread NMO pathology was seen following 3-days infusion of NMO-IgG ${ }^{\mathrm{CDC}+}$ and complement in wild-type mice, and of (non-mutated) NMO-IgG and complement in CD59-null mice (Figure 3B).

One of the characteristics of NMO pathology is inflammatory cell infiltration. After 3-days infusion with NMO-IgG or NMO-IgG ${ }^{\mathrm{CDC}+}$ and complement, optic nerves showed inflammatory cell infiltration on hematoxylin and eosin staining (Figure 3C), mainly mononuclear inflammatory cells. Inflammatory cell infiltration was not seen with control IgG with complement, NMO-IgG ${ }^{\mathrm{CDC}+}$ alone, or
NMO-IgG with complement in $\mathrm{AQP}^{-/-}$mice (data not shown).

\section{Characterization of optic neuritis pathology produced by} infusion of neuromyelitis optica immunoglobulin G antibody

The characteristic features of NMO pathology include AQP4, GFAP, myelin loss and inflammatory cell infiltration, as shown above, as well as BBB disruption, and inflammation with microglial activation and macrophage and granulocyte infiltration [6-8]. Figure 4A shows focal albumin extravasation in areas of NMO pathology, demonstrating BBB leakage. Localized inflammation was also evident with increased Iba1 (microglial marker) and CD45 (leukocyte) immunofluorescence (Figure 4A). Albumin extravasation and inflammation were absent in mice receiving a 3-day infusion of control IgG and 


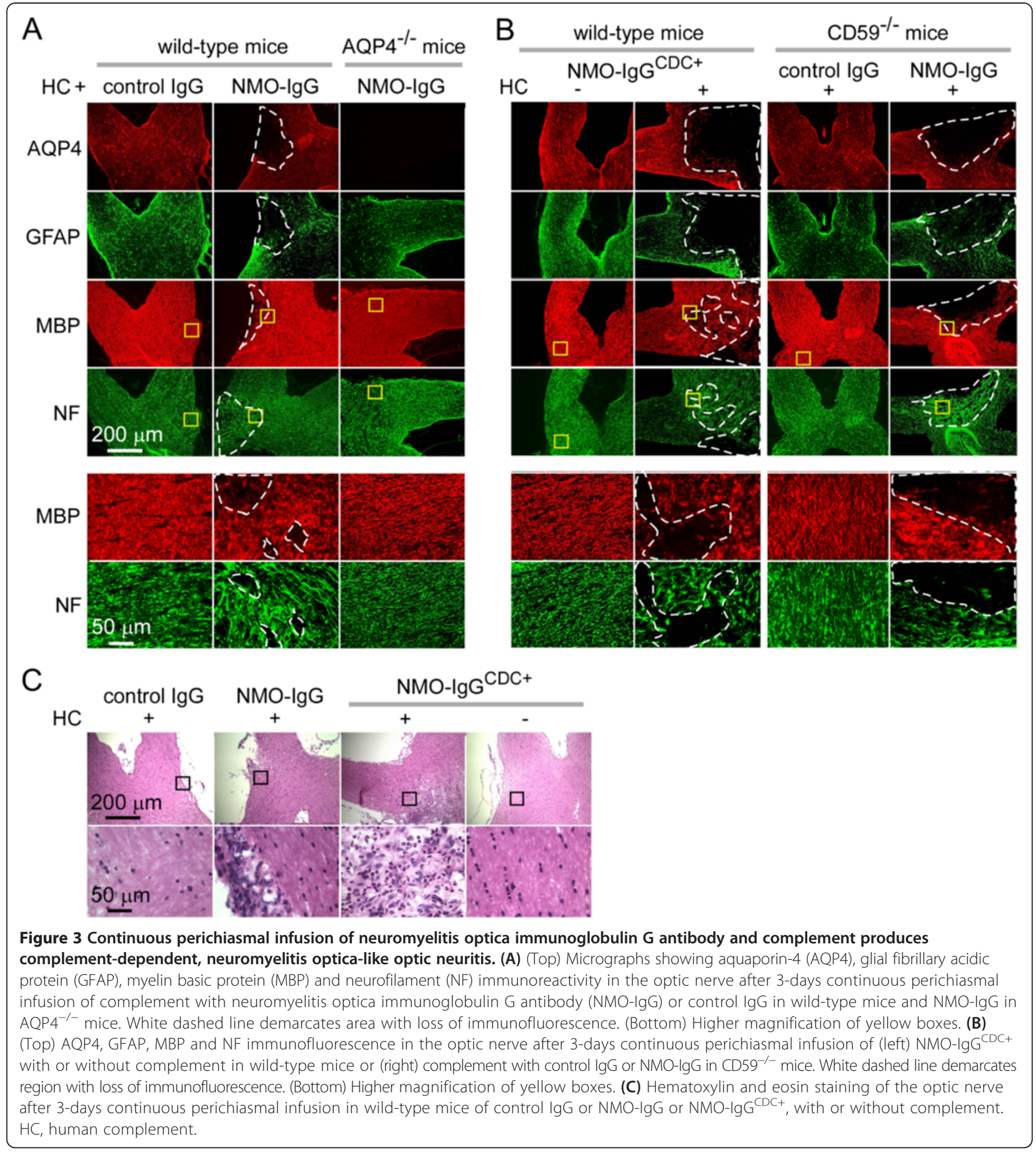

complement, and increased in wild-type mice receiving NMO-IgG ${ }^{\mathrm{CDC}+}$ and complement, and in CD59-null mice receiving NMO-IgG and complement.

The composition of the CD45-positive cell infiltrate was determined using antibodies against cell-specific markers. Figure 4B shows positive immunofluorescence for macrophages (F4/80), eosinophils (Siglec-F) and neutrophils (Ly-6G), with quantification showing a greater number of macrophages than granulocytes in this model. Cell-specific immunofluorescence was absent in mice receiving a 3-day infusion of control IgG and complement.

\section{Retinal ganglion cell loss}

A consequence of NMO ON is retrograde RGC loss leading to visual deficit. We quantified RGC number in whole-retina mounts at 7 days after delivery of NMO-IgG 


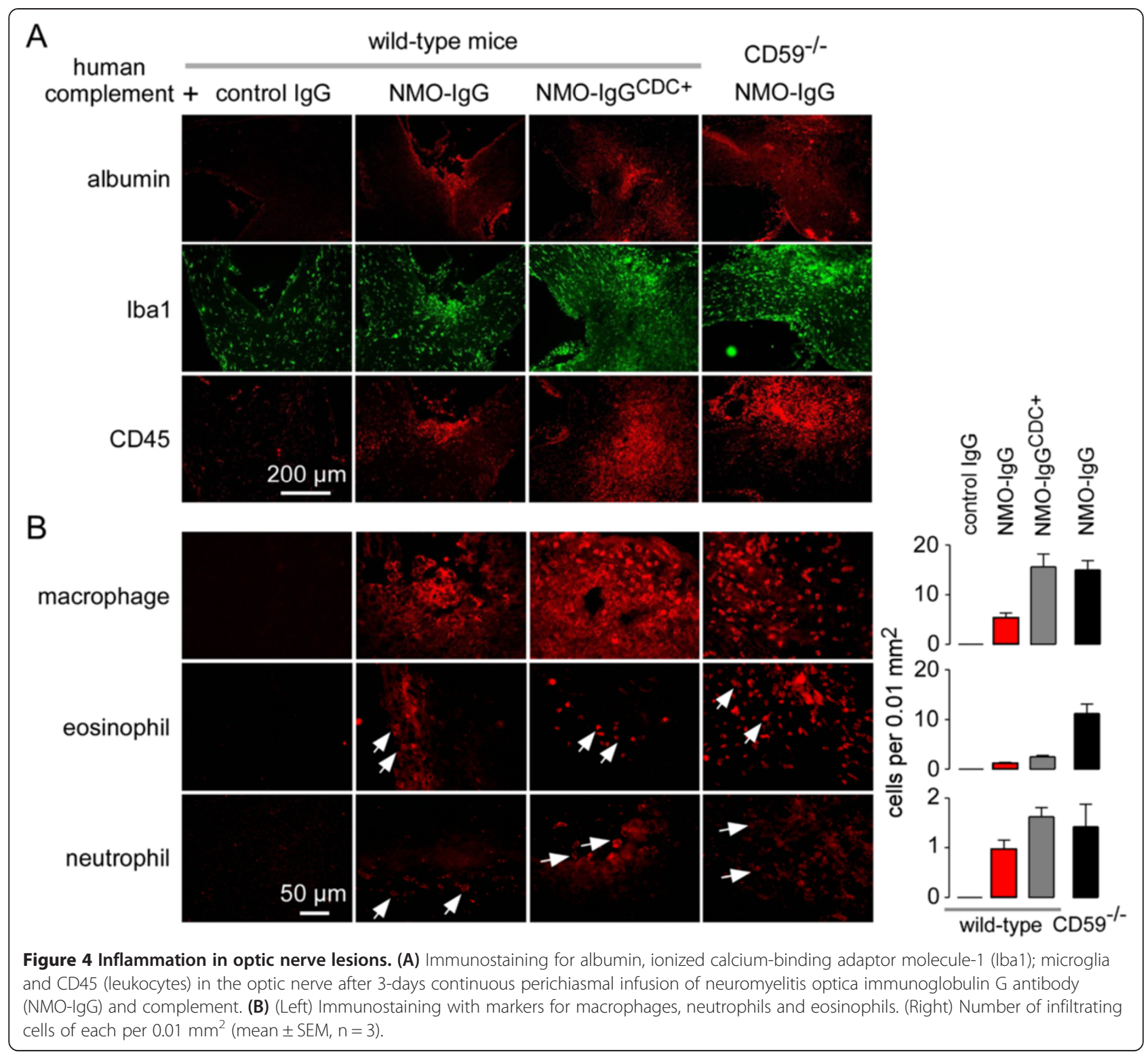

and human complement to posterior optic nerve (Figure 5A). Figure 5B,C shows no clear reduction in the number of RGCs in mice receiving a 3-day infusion of NMO-IgG and complement compared to control IgG. RGC number was reduced by $28 \%$ in wild-type mice administered NMO-IgG ${ }^{\mathrm{CDC}+}$ and complement and by $21 \%$ in $\mathrm{CD} 59^{-/-}$mice injected with NMO-IgG. No RGC loss was seen in $\mathrm{AQP} 4^{-/-}$mice injected with NMO-IgG. Optic nerve crush injury was used as a positive control of RGC damage.

\section{Discussion}

Current understanding of NMO pathogenesis comes largely from data on brain and spinal cord, as there is little descriptive pathology of optic nerves in human NMO and adequate animal models of NMO ON have not been developed. The bulk of evidence supports a pathogenesis mechanism that involves NMO-IgG access to the central nervous system and binding to AQP4 on astrocytes, which causes complement- and cell-mediated cytotoxicity [22,26,39-42]. The primary astrocyte damage initiates an inflammatory reaction with cytokine release, granulocyte and macrophage infiltration, and further BBB disruption, which produces secondary oligodendrocyte injury, demyelination and neuron loss. This mechanism is supported by pathology in human spinal cord and brain $[43,44]$, by brain pathology in mice following passive transfer of NMO-IgG by intracerebral injection [23], and by ex vivo studies in spinal cord slice cultures exposed to NMO-IgG and various effector molecules and cells [45]. It has been assumed without direct evidence that a similar pathogenesis mechanism applies to 


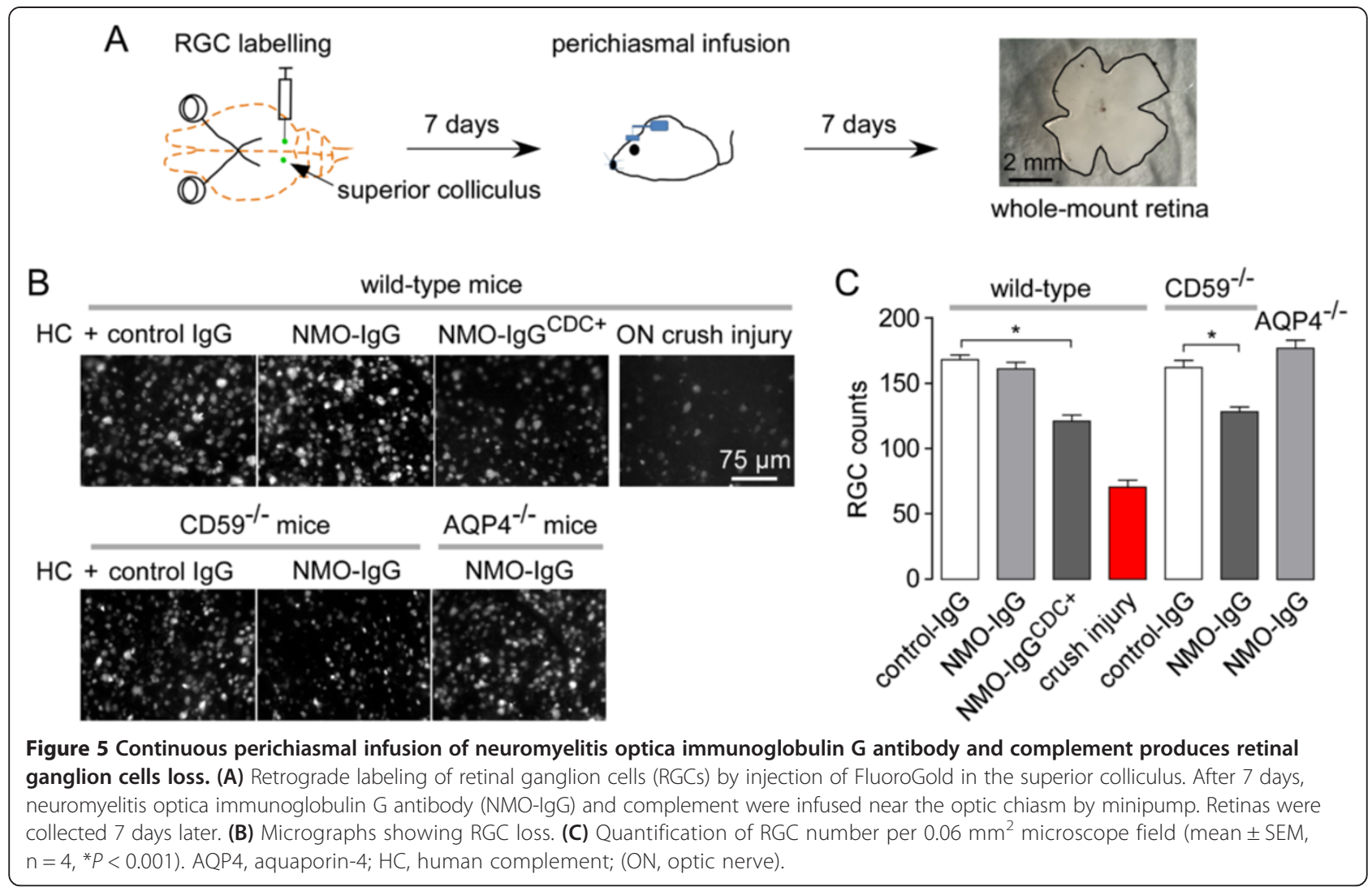

NMO ON. Studies done in ex vivo optic nerve cultures exposed to NMO-IgG and complement showed an astrocytopathy with demyelination, but this model is limited by the short-term ( $\sim$ day) viability of optic nerve cultures [45].

The main finding of the study here is that passive transfer of NMO-IgG and human complement to mice by continuous intracranial infusion near the optic chiasm produces optic nerve lesions with loss of AQP4 and GFAP immunoreactivity, demyelination, and inflammation with prominent macrophage infiltration. Optic nerve pathology was exacerbated when NMO-IgG was administered to CD59 knockout mice or when a mutated NMO antibody with enhanced complement effector function was administered to wild-type mice, supporting a central role of complement in NMO ON in our model. Control studies, including infusions in AQP4 knockout mice, indicated that the pathological changes require NMO-IgG, complement and AQP4. The passive transfer model of NMO ON established here should be useful in studying mechanisms of NMO pathogenesis specific to the anterior visual pathway, as well as in evaluating potential vision-preserving therapies using clinically relevant in vivo anatomic and functional outcome measures.

Prior models of general neuroinflammation include optic nerve pathology, though the pathogenesis mechanisms are very different from that of NMO, which involves a humorally mediated astrocytopathy. As mentioned in the Introduction, $\mathrm{ON}$ is a well-described feature of experimental autoimmune encephalomyelitis. ON has also been seen in a subpopulation of transgenic mice expressing myelin oligodendrocyte glycoprotein (MOG)-specific T cell receptors [46]. Crossing this mouse with a MOG-specific Ig heavy-chain knock-in mouse produced mice with both $\mathrm{T}$ and B cell MOG reactivity [29]. This double transgenic mouse manifests selective optic nerve and spinal cord pathology (with 60\% penetrance) and a Th17 differentiation bias, reminiscent of NMO [47]. While $\mathrm{ON}$ is seen in these various models, they are probably not useful to study NMO pathogenesis mechanisms or test NMO therapeutics.

Several approaches to deliver NMO-IgG and complement were tested to produce robust ON in mice. Delivery of NMO-IgG and complement to the anterior optic nerve following lateral canthotomy did not produce optic nerve pathology, probably because of limited access of infused macromolecules to the ensheathed anterior optic nerve. Though intravitreal injection of NMO-IgG and complement resulted in NMO-IgG binding to AQP4 in retinal Müller cells, no retinal pathology was seen, perhaps because of limited access of some complement components to inner retinal layers. Also, intravitreally delivered solutes and macromolecules are 
unable to diffuse into the optic nerve. From these initial studies, we postulated that delivery of NMO-IgG and complement near the unsheathed perichiasmal posterior optic nerve might produce NMO ON. Though a single intracerebral injection of NMO-IgG and complement with the needle tip near the optic chiasm resulted in some NMO-IgG binding to optic nerve, as well as NMO pathology in brain near the optic nerve, little $\mathrm{NMO}$ pathology was found. Robust NMO pathology required continuous intracerebral injection of NMO-IgG and complement near the optic nerve. We conclude that the sustained exposure of target tissues to pathogenic macromolecules afforded by continuous infusion better recapitulates human $\mathrm{NMO}$ in which progressive pathology involves an amplifying cycle of astrocyte cytotoxicity, inflammation and BBB disruption. We cannot exclude, however, the possibility that the prechiasmal optic nerve and optic chiasm may be more susceptible to NMO-IgG-mediated pathology than the anterior optic nerve.

Though the NMO ON model developed here produced robust lesions with characteristic NMO pathology, there are a number of limitations of the model and potential directions for future advances. Continuous intracerebral infusion with precise needle placement is invasive and technically challenging. The direct administration of human complement, which was necessary because of the weak activity of mouse complement and the presence of complement inhibitory factor(s) in mouse serum [48], does not accurately recapitulate the human disease in which endogenous complement proteins derive primarily from the serum. We recently established a rat model of NMO involving intracerebral administration of NMO-IgG without added complement, which produced robust NMO pathology in brain around the needle track [16]. Pathology required active rat complement, as complement inactivation by cobra venom factor prevented the astrocyte cytotoxicity and demyelination. In a recent variation of the rat model, NMO pathology was produced in brain by peripheral NMO-IgG administration and focal mechanical BBB disruption (Asavapanumas and colleagues, unpublished results). Models of $\mathrm{NMO} \mathrm{ON}$ in rats involving peripheral or optic nerve-targeted NMO-IgG delivery, perhaps in combination with maneuvers to disrupt the blood-optic nerve barrier, may produce $\mathrm{ON}$ without the need to administer complement.

It remains unclear why NMO pathology is primarily restricted to optic nerve and spinal cord, and to a lesser extent in brain, with little or no pathology in peripheral AQP4-expressing tissues. Optic nerve susceptibility in $\mathrm{NMO}$ is unlikely due solely to NMO-IgG access, and may involve impaired diffusion of NMO-IgG, soluble pro-inflammatory factors and complement proteins from focal areas of central nervous system entry. Optic nerve susceptibility in NMO might also arise from the high AQP4 expression in the optic nerve compared to brain [47] and the abundance of large orthogonal arrays of particles in perivascular astrocytic end-feet of the optic nerve [49-51] that promote tight binding of AQP4-IgG and efficient CDC [52]. Plasmablasts in the cerebrospinal fluid secreting NMO-IgG locally [22] and/or regional variations in the expression of complement regulator or key $\mathrm{BBB}$ proteins may also play a role.

\section{Conclusions}

Passive transfer of NMO-IgG, when supplemented with human complement, produced $\mathrm{ON}$ in mice with characteristic NMO pathology. Development of robust pathology required continuous exposure of the posterior optic nerve to NMO-IgG and complement, which was accomplished by 3-days intercerebral infusion using an implanted mini-pump with needle positioned near the optic chiasm. Our data show that, as found in brain, passive transfer of NMO-IgG and complement is sufficient to produce $\mathrm{ON}$ in mice. NMO ON models should be useful in testing novel disease-modifying therapeutics aimed at preserving vision.

\section{Abbreviations \\ AQP4: aquaporin-4; BBB: blood-brain barrier; GFAP: glial fibrillary acidic protein; Iba1: ionized calcium-binding adaptor molecule-1; \\ lgG: immunoglobulin G; MBP: myelin basic protein; MOG: myelin oligodendrocyte glycoprotein; NMO: neuromyelitis optica; NMO-lgG: neuromyelitis optica immunoglobulin G antibody; ON: optic neuritis; RGC: retinal ganglion cell; UCSF: University of California, San Francisco.}

\section{Competing interests}

The authors declare that they have no competing interests.

\section{Authors' contributions}

NA and JR carried out experimental work and wrote the manuscript draft MCP, JLB, MHL and ASV designed experiments and edited the manuscript. All authors read and approved the final manuscript.

\section{Acknowledgments}

Supported by grants EY13574, EB00415, DK35124, HL73856, DK86125 and DK72517 from the National Institutes of Health, and a grant from the Guthy-Jackson Charitable Foundation. We thank Accelerated Cure (Waltham, MA, USA) for providing human NMO sera.

\section{Author details}

'Department of Medicine and Physiology, University of California, 1246 Health Sciences East Tower, San Francisco, CA 94143-0521, USA. ²Academic Neurosurgery Unit, St. George's, University of London, London SW17 ORE, UK. ${ }^{3}$ Departments of Neurology and Ophthalmology, University of Colorado Denver, Aurora, CO 80045, USA. ${ }^{4}$ Department of Ophthalmology, University of California, San Francisco, CA 94143, USA

Received: 2 November 2013 Accepted: 13 January 2014 Published: 27 January 2014

\section{References}

1. Jarius S, Paul F, Franciotta D, Waters P, Zipp F, Hohlfeld R, Vincent A Wildemann B: Mechanisms of disease: aquaporin-4 antibodies in neuromyelitis optica. Nat Clin Pract Neurol 2008, 4:202-214.

2. Jacob A, McKeon A, Nakashima I, Sato DK, Elsone L, Fujihara K, de Seze J: Current concept of neuromyelitis optica (NMO) and NMO spectrum disorders. J Neurol Neurosurg Psychiatry 2013, 84:922-930. 
3. Wingerchuk DM, Lennon VA, Lucchinetti CF, Pittock SJ, Weinshenker BG: The spectrum of neuromyelitis optica. Lancet Neurol 2007, 6:805-815.

4. Jarius S, Wildemann B: AQP4 antibodies in neuromyelitis optica diagnostic and pathogenetic relevance. Nat Rev Neurol 2010, 6:383-392.

5. Lennon VA, Kryzer TJ, Pittock SJ, Verkman AS, Hinson SR: IgG marker of optic-spinal multiple sclerosis binds to the aquaporin-4 water channel. J Exp Med 2005, 202:473-477.

6. Kira J: Autoimmunity in neuromyelitis optica and opticospinal multiple sclerosis: astrocytopathy as a common denominator in demyelinating disorders. J Neurol Sci 2011, 311:69-77.

7. Misu T, Fujihara K, Kakita A, Konno H, Nakamura M, Watanabe S, Takahashi T, Nakashima I, Takahashi H, Itoyama Y: Loss of aquaporin 4 in lesions of neuromyelitis optica: distinction from multiple sclerosis. Brain 2007, 130:1224-1234.

8. Papadopoulos MC, Verkman AS: Aquaporin 4 and neuromyelitis optica. Lancet Neurol 2012, 11:535-544.

9. Kim SH, Kim W, Huh SY, Lee KY, Jung IJ, Kim HJ: Clinical efficacy of plasmapheresis in patients with neuromyelitis optica spectrum disorder and effects on circulating anti-aquaporin-4 antibody levels. J Clin Neurol 2013, 9:36-42.

10. Greenberg BM, Graves D, Remington G, Hardeman P, Mann M, Karandikar N, Stuve O, Monson N, Frohman E: Rituximab dosing and monitoring strategies in neuromyelitis optica patients: creating strategies for therapeutic success. Mult Scler 2012, 18:1022-1026.

11. Levin MH, Bennett $J \mathrm{~L}$, Verkman AS: Optic neuritis in neuromyelitis optica. Prog Retin Eye Res 2013, 36:159-171

12. Beck RW, Cleary PA, Anderson MM Jr, Keltner JL, Shults WT, Kaufman DI, Buckley EG, Corbett JJ, Kupersmith MJ, Miller NR, Savino PJ, Guy JR, Trobe JD, Mccrary JA, Smith CH, Chrousos GA, Thompson HS, Katz BJ, Brodsky MC, Goodwin JA, Atwell CW: A randomized, controlled trial of corticosteroids in the treatment of acute optic neuritis: the optic neuritis study group. $N$ Engl J Med 1992, 326:581-588.

13. Optic Neuritis Study Group, Gal RL: Visual function 15 years after optic neuritis: a final follow-up report from the Optic Neuritis Treatment Trial. Ophthalmology 2008, 115:1079-1082.

14. Zhang $H$, Verkman AS: Eosinophil pathogenicity mechanisms and therapeutics in neuromyelitis optica. J Clin Invest 2013, 123:2306-2316.

15. Saadoun S, Waters P, MacDonald C, Bell BA, Vincent A, Verkman AS, Papadopoulos MC: Neutrophil protease inhibition reduces neuromyelitis optica-immunoglobulin G-induced damage in mouse brain. Ann Neurol 2012, 71:323-333.

16. Asavapanumas N, Ratelade J, Verkman AS: Unique neuromyelitis optica pathology produced in naive rats by intracerebral administration of NMO-IgG. Acta Neuropathol. In press 2014, [Epub ahead of print].

17. Tradtrantip L, Zhang H, Saadoun S, Phuan PW, Lam C, Papadopoulos MC, Bennett $J$, Verkman AS: Anti-aquaporin-4 monoclonal antibody blocker therapy for neuromyelitis optica. Ann Neurol 2012, 71:314-322.

18. Phuan PW, Zhang $H$, Asavapanumas $N$, Leviten M, Rosenthal A Tradtrantip L, Verkman AS: C1q-targeted monoclonal antibody prevents complement-dependent cytotoxicity and neuropathology in in vitro and mouse models of neuromyelitis optica. Acta Neuropathol 2013, 125:829-840.

19. Pittock SJ, Lennon VA, McKeon A, Mandrekar J, Weinshenker BG, Lucchinetti CF OToole O, Wingerchuk DM: Eculizumab in AQP4-IgG-positive relapsing neuromyelitis optica spectrum disorders: an open-label pilot study. Lancet Neurol 2013, 12:554-562.

20. Kinoshita M, Nakatsuji Y, Kimura T, Moriya M, Takata K, Okuno T, Kumanogoh A, Kajiyama K, Yoshikawa H, Sakoda S: Neuromyelitis optica: passive transfer to rats by human immunoglobulin. Biochem Biophys Res Commun 2009, 386:623-627.

21. Bradl M, Misu T, Takahashi T, Watanabe M, Mader S, Reindl M, Adzemovic M Bauer J, Berger T, Fujihara K, Itoyama Y, Lassmann H: Neuromyelitis optica: pathogenicity of patient immunoglobulin in vivo. Ann Neurol 2009, 66:630-643

22. Bennett JL, Lam C, Kalluri SR, Saikali P, Bautista K, Dupree C, Glogowska M, Case D, Antel JP, Owens GP, Gilden D, Nessler S, Stadelmann C, Hemmer B: Intrathecal pathogenic anti-aquaporin-4 antibodies in early neuromyelitis optica. Ann Neurol 2009, 66:617-629.

23. Saadoun S, Waters P, Bell BA, Vincent A, Verkman AS, Papadopoulos MC: Intra-cerebral injection of neuromyelitis optica immunoglobulin $\mathrm{G}$ and human complement produces neuromyelitis optica lesions in mice. Brain 2010, 133:349-361.

24. Ma T, Yang B, Gillespie A, Carlson EJ, Epstein CJ, Verkman AS: Generation and phenotype of a transgenic knockout mouse lacking the mercurial-insensitive water channel aquaporin-4. J Clin Invest 1997, 100:957-962.

25. Crane JM, Lam C, Rossi A, Gupta T, Bennett JL, Verkman AS: Binding affinity and specificity of neuromyelitis optica autoantibodies to aquaporin$4 \mathrm{m1} / \mathrm{m} 23$ isoforms and orthogonal arrays. J Biol Chem 2011, 286:16516-16524.

26. Ratelade J, Asavapanumas N, Ritchie AM, Wemlinger S, Bennett JL, Verkman AS: Involvement of antibody-dependent cell-mediated cytotoxicity in inflammatory demyelination in a mouse model of neuromyelitis optica. Acta Neuropathol 2013, 126:699-709.

27. Moore GL, Chen H, Karki S, Lazar GA: Engineered Fc variant antibodies with enhanced ability to recruit complement and mediate effector functions. MAbs 2010, 2:181-189.

28. Ruiz-Ederra J, Verkman AS: Mouse model of sustained elevation in intraocular pressure produced by episcleral vein occlusion. Exp Eye Res 2006, 82:879-884

29. Bettelli E, Baeten D, Jager A, Sobel RA, Kuchroo VK: Myelin oligodendrocyte glycoprotein-specific T and B cells cooperate to induce a Devic-like disease in mice. J Clin Invest 2006, 116:2393-2402.

30. Zuo L, Khan RS, Lee V, Dine K, Wu W, Shindler KS: SIRT1 promotes RGC survival and delays loss of function following optic nerve crush. Invest Ophthalmol Vis Sci 2013, 54:5097-5102.

31. Hamann S, Zeuthen T, La Cour M, Nagelhus EA, Ottersen OP, Agre P, Nielsen S: Aquaporins in complex tissues: distribution of aquaporins 1-5 in human and rat eye. Am J Physiol 1998, 274:C1332-C1345.

32. Green AJ, Cree BA: Distinctive retinal nerve fibre layer and vascular changes in neuromyelitis optica following optic neuritis. J Neurol Neurosurg Psychiatry 2009, 80:1002-1005.

33. Gelfand JM, Cree BA, Nolan R, Arnow S, Green AJ: Microcystic inner nuclear layer abnormalities and neuromyelitis optica. JAMA Neurol 2013, 70:629-633.

34. Sotirchos ES, Saidha S, Byraiah G, Mealy MA, Ibrahim MA, Sepah YJ, Newsome SD, Ratchford JN, Frohman EM, Balcer LJ, Crainiceanu CM, Nguyen QD, Levy M, Calabresi PA: In vivo identification of morphologic retinal abnormalities in neuromyelitis optica. Neurology 2013, 80:1406-1414.

35. Ludwin SK: Phagocytosis in the rat optic nerve following Wallerian degeneration. Acta Neuropathol 1990, 80:266-273.

36. Hickman SJ, Toosy AT, Jones SJ, Altmann DR, Miszkiel KA, MacManus DG, Barker GJ, Plant GT, Thompson AJ, Miller DH: Serial magnetization transfer imaging in acute optic neuritis. Brain 2004, 127:692-700.

37. Gasque P, Morgan BP: Complement regulatory protein expression by a human oligodendrocyte cell line: cytokine regulation and comparison with astrocytes. Immunology 1996, 89:338-347.

38. Spiller OB, Moretto G, Kim SU, Morgan BP, Devine DV: Complement expression on astrocytes and astrocytoma cell lines: failure of complement regulation at the C3 level correlates with very low CD55 expression. J Neuroimmunol 1996, 71:97-106.

39. Hinson SR, Pittock SJ, Lucchinetti CF, Roemer SF, Fryer JP, Kryzer TJ, Lennon VA: Pathogenic potential of IgG binding to water channel extracellular domain in neuromyelitis optica. Neurology 2007, 69:2221-2231.

40. Hinson SR, McKeon A, Fryer JP, Apiwattanakul M, Lennon VA, Pittock SJ: Prediction of neuromyelitis optica attack severity by quantitation of complement-mediated injury to aquaporin-4-expressing cells. Arch Neurol 2009, 66:1164-1167.

41. Sabater L, Giralt A, Boronat A, Hankiewicz K, Blanco Y, Llufriu S, Alberch J, Graus F, Saiz A: Cytotoxic effect of neuromyelitis optica antibody (NMO-lgG) to astrocytes: an in vitro study. J Neuroimmuno/ 2009, 215:31-35.

42. Vincent T, Saikali P, Cayrol R, Roth AD, Bar-Or A, Prat A, Antel JP: Functional consequences of neuromyelitis optica-lgG astrocyte interactions on blood-brain barrier permeability and granulocyte recruitment. J Immunol 2008, 181:5730-5737

43. Roemer SF, Parisi JE, Lennon VA, Benarroch EE, Lassmann H, Bruck W, Mandler RN, Weinshenker BG, Pittock SJ, Wingerchuk DM, Lucchinetti CF: Pattern-specific loss of aquaporin-4 immunoreactivity distinguishes neuromyelitis optica from multiple sclerosis. Brain 2007, 130:1194-1205.

44. Misu T, Hoftberger R, Fujihara K, Wimmer I, Takai $Y$, Nishiyama S, Nakashima I, Konno H, Bradl M, Garzuly F, Itoyama Y, Aoki M, Lassmann H: Presence of six different lesion types suggests diverse mechanisms of tissue injury in neuromyelitis optica. Acta Neuropathol 2013, 125:815-827. 
45. Zhang $H$, Bennett $J$, Verkman AS: Ex vivo spinal cord slice model of neuromyelitis optica reveals novel immunopathogenic mechanisms. Ann Neurol 2011, 70:943-954.

46. Bettelli E, Pagany M, Weiner HL, Linington C, Sobel RA, Kuchroo VK: Myelin oligodendrocyte glycoprotein-specific T cell receptor transgenic mice develop spontaneous autoimmune optic neuritis. J Exp Med 2003, 197:1073-1081.

47. Varrin-Doyer M, Spencer CM, Schulze-Topphoff U, Nelson PA, Stroud RM, Cree BA, Zamvil SS: Aquaporin 4-specific T cells in neuromyelitis optica exhibit a Th17 bias and recognize Clostridium ABC transporter. Ann Neurol 2012, 72:53-64.

48. Bergman I, Basse PH, Barmada MA, Griffin JA, Cheung NK: Comparison of in vitro antibody-targeted cytotoxicity using mouse, rat and human effectors. Cancer Immunol Immunother 2000, 49:259-266.

49. Bauerle $\mathrm{C}$, Wolburg $\mathrm{H}$ : Astrocytes in the nonmyelinated lamina cribrosa of the rat are less polarized than in the optic nerve proper: a freezefracture study. Glia 1993, 9:238-241.

50. Amiry-Moghaddam M, Xue R, Haug FM, Neely JD, Bhardwaj A, Agre P, Adams ME, Froehner SC, Mori S, Ottersen OP: Alpha-syntrophin deletion removes the perivascular but not endothelial pool of aquaporin-4 at the blood-brain barrier and delays the development of brain edema in an experimental model of acute hyponatremia. FASEB J 2004, 18:542-544.

51. Nicchia GP, Cogotzi L, Rossi A, Basco D, Brancaccio A, Svelto M, Frigeri A: Expression of multiple AQP4 pools in the plasma membrane and their association with the dystrophin complex. J Neurochem 2008, 105:2156-2165.

52. Phuan PW, Ratelade J, Rossi A, Tradtrantip L, Verkman AS: Complementdependent cytotoxicity in neuromyelitis optica requires aquaporin-4 protein assembly in orthogonal arrays. J Biol Chem 2012, 287:13829-13839.

doi:10.1186/1742-2094-11-16

Cite this article as: Asavapanumas et al: Experimental mouse model of optic neuritis with inflammatory demyelination produced by passive transfer of neuromyelitis optica-immunoglobulin G. Journal of Neuroinflammation 2014 11:16

\section{Submit your next manuscript to BioMed Central and take full advantage of:}

- Convenient online submission

- Thorough peer review

- No space constraints or color figure charges

- Immediate publication on acceptance

- Inclusion in PubMed, CAS, Scopus and Google Scholar

- Research which is freely available for redistribution 